\title{
Morbid Obesity
}

National Cancer Institute

\section{Source}

National Cancer Institute. Morbid Obesity. NCI Thesaurus. Code C34858.

An excess of body weight, normally defined as an individual with a body mass index

greater than 35 or a body weight greater than one hundred percent of ideal body weight. 